The Political Control of Bureaucracies under Asymmetric Information

Author(s): Jeffrey S. Banks and Barry R. Weingast

Source: American Journal of Political Science, Vol. 36, No. 2 (May, 1992), pp. 509-524

Published by: Midwest Political Science Association

Stable URL: http://www.jstor.org/stable/2111488

Accessed: 18-03-2016 17:06 UTC

Your use of the JSTOR archive indicates your acceptance of the Terms \& Conditions of Use, available at http://www.jstor.org/page/ info/about/policies/terms.jsp

JSTOR is a not-for-profit service that helps scholars, researchers, and students discover, use, and build upon a wide range of content in a trusted digital archive. We use information technology and tools to increase productivity and facilitate new forms of scholarship. For more information about JSTOR, please contact support@jstor.org. 


\title{
The Political Control of Bureaucracies under Asymmetric Information*
}

\author{
Jeffrey S. Banks, Department of Political Science and Department of \\ Economics, University of Rochester \\ Barry R. Weingast, Hoover Institution, Stanford University
}

We analyze a model of interest group influence where this influence arises from a group's ability to provide relevant information to political actors about regulatory performance. The model rests on three premises: (1) bureaucrats possess an informational advantage, vis-d̀-vis their political overseers, concerning policy relevant variables; (2) this informational advantage is potentially exploitable by the agency; and (3) politicians anticipate this exploitation and adapt to it in their design of agencies. We show that a major consequence of this anticipation and adaptation is service to organized interest groups.

The relationship between interest groups and policy choice has long been of interest to scholars of regulation, and they play a central role in a variety of theories. These include the "capture" hypothesis of Bernstein (1955) and Huntington (1952), the "cartel by design" hypothesis of Kolko (1965) and Stigler (1971), the famous fourfold table of Wilson (1974), and, more recently, theories in which political actors bias policy decisions in favor of their constituents (e.g., Fiorina 1981; Moe 1989; McCubbins, Noll, and Weingast 1989). ${ }^{1}$ While the specific pattern of interest group influence differs considerably across these theories, the mechanics of interest group influence typically fall into two categories. One approach focuses on the electoral role of interest groups and their ability to mobilize resources and votes (most notably Stigler 1971; Peltzman 1976). A second approach focuses on the role of interest groups as sources of information for both bureaucrats and politicians (see such disparate models as Fiorina 1981; McCubbins and Schwartz 1984; Moe 1989; Wilson 1980). While Stigler and Peltzman have formalized the former approach, no one has formalized the latter.

The purpose of this paper is to provide a model of interest group influence, distinct from their electoral effects, based on their ability to provide information to political actors about regulatory performance. The model rests on three premises. First, bureaucrats are experts in their policy areas and have substantial informational advantages with respect to their political overseers. Second, this informational advantage is potentially exploitable by the agency. Third, politicians

*The authors gratefully acknowledge the financial support of the National Science Foundation under grants SES 87-00468 and SES 86-17516, respectively. We also thank Paul Rubin and Jon Bendor for detailed and valuable comments on an earlier draft.

'Noll (1988) provides an excellent review of these literatures.

American Journal of Political Science, Vol. 36, No. 2, May 1992, Pp. 509-24

(C) 1992 by the University of Texas Press, P.O. Box 7819, Austin, TX 78713 
anticipate this problem and adapt to it. We show that a major consequence of this anticipation and adaptation is service to organized groups.

Building on the model in Banks (1989), we begin with a situation like that studied by Niskanen (1971): a politician desires some service to be provided by an agency. Both the politician and the agency know the politician's value of the service, but only the agency knows the cost of providing the service. In the Niskanen model, this allows the agency to present the sponsor with a take-it-orleave-it offer to produce the service in return for a budget named by the agency. Since the politician will accept any request as long as it is less than or equal to his reservation budget, a budget-maximizing agency will request this level, thereby receiving all of the available gains from the transaction. Moreover, as Niskanen shows, this holds regardless of the true cost of the service, provided the politician can not learn the true cost.

While the Niskanen (1971) model focuses on one of the key problems of the bureaucracy, it is unlikely to give a good characterization of bureaucratic politics because it ignores the ability of politicians to adapt to it. A range of scholars in the "political control" tradition have emphasized this point (e.g., Bendor, Taylor, and Van Gaalen 1985; Fiorina 1981; McCubbins and Schwartz 1984; McCubbins, Noll, and Weingast 1989; Miller and Moe 1983; Moe 1989; Weingast 1984). According to Fiorina $(1981,333)$, "The bureaucracy is not out of control because Congress controls the bureaucracy and Congress gives us the kind of bureaucracy it wants." Similarly, Bendor, Taylor, and Van Gaalen (1985) note that since politicians can make themselves better off by shifting some resources to monitoring bureaus that are absorbing revenues in ways that do not benefit powerful constituencies, it is unlikely that an enduring pattern of budgetary expansion is due to bureaucratic "hoodwinking" of the public.

The interaction between the politicians and the agency becomes more interesting when we allow the former to investigate or "audit" the latter's production process, where such an action reveals to the politicians the true cost of the agency's service; the politicians can subsequently set the budget equal to this cost. However, if auditing is costly to the politician it will not always be optimal to adopt this strategy. Under these circumstances, then, the agency cannot extract all of the possible gains, but still extracts some of them. ${ }^{2}$

In what follows, we utilize the Banks (1989) model to derive an important comparative statics result: the higher the costs of auditing, the greater the amount the agency can extract. This provides the link with the literature that focuses on the role of a politician's constituency in mitigating an agency's informational advantage (notably McCubbins and Schwartz 1984). Typically, organized con-

${ }^{2}$ Bendor, Taylor, and Van Gaalen $(1985,1987)$ also explore models in which the politician can audit the agency; however, theirs is set up in "principal-agent" framework, in contrast to the "sequentially rational" framework adopted here. See Banks (1989) for a fuller discussion of the differences between their model and ours. 
stituents have access to expertise and information that can rival that of an agency. If the agency is designed to serve the constituents' interests, then it will be in the latter's interest to provide the information to their representatives so that the politicians can use it to limit agency exploitation. In this way, constituents subsidize the costs to the politicians of learning an agency's true costs.

This formulation yields surprising results for the question of bureaucratic control. To see this, we follow Fiorina (1985) and McCubbins (1985) and ask, How do politicians decide which agencies to create? The comparative statics result noted above suggests one answer. While all agencies have the same potential for asymmetric information, each faces a different interest group with a different level of access to the information held by the agency. From the politician's standpoint, this means that agencies may be created with virtually no ability to exploit their position, namely, those where the relevant constituents have a low cost of access to information. Because these agencies are unable to exploit their information, politicians and their constituents capture most of the available rents. A second major difference among potential agencies concerns the extent of these available rents. Clearly, not all agencies are equally desirable for politicians, since agencies have varying abilities to serve constituencies and generate votes. When selecting or creating a single agency, therefore, a politician will consider an agency's value vis-à-vis alternative agencies as well. Thus, depending on the characteristics of the potential agencies, the politician's selection of an "optimal" agency will involve a trade-off between the value an agency generates and the ability of the politician to secure that value through limitations on the agency's informational advantage.

The model yields three important results. First, while an informational advantage potentially allows an agency to extract large amounts of the gains from politicians, agencies are likely to be created only in those areas where the advantage is minimal relative to their political value. Even though potential asymmetries are important and play a large role in the selection of agency creation, those agencies that actually are created suffer from this problem only to a limited degree (or possess a political value far outweighing any such problems).

The second implication of the approach is derived from the first and concerns the efficiency consequences of bureaucracy. Previous approaches have focused on inefficiencies that arise because bureaucracies provide too many services, or because a given service is provided at too high a price (Niskanen 1971). In contrast, our model has inefficiencies that arise through the selection process itself. Namely, there may exist potential agencies that are not created because politicians have no means of preventing the agency from extracting a disproportionate share of the rents. The politician therefore might prefer a less valuable agency with lower auditing costs, since the net return from this agency is greater.

Returning to the role of interest groups in regulation, a final conclusion of the model is that, even if organized constituencies possess limited electoral ad- 
vantages, agencies should be observed to serve them because politicians are biased in favor of creating agencies to serve them. The source of bias characterized in this paper arises not because of the differential electoral rewards but because interest groups play an active role in the production and monitoring process by providing politicians with a source of information independent of the agency. Put simply, agencies designed to serve unorganized groups allow bureaucrats to extract too much of the gains from policymaking at the expense of both politicians and their constituents, and hence politicians fail to create them because they are not worth the costs.

This paper proceeds as follows. Section 1 details the basic model of information asymmetry between politicians and agencies, showing how an agency potentially may extract gains from its political overseers as a function of the cost of auditing and the value of the agency. Section 2 describes the politicians' preferences over agencies, where these preferences are induced by the equilibrium behavior of the parties in the basic model of section 1 and considers the selection of an optimal agency. Section 3 then turns to the role of interest groups in relation to auditing costs, agency value, and the characteristics of the set of potential feasible agencies, and discusses the efficiency consequences of the model. Our conclusions follow.

\section{A Model of the Politician-Agency Relationship}

In this section, we consider the model due to Banks (1989) of the interaction between a politician, $P$, and an agency, $A$, where $A$ provides costly services which are valued by $P$, and where $P$ is the sole source of funding for these services. The value of the agency's services to $P$ is denoted by $v, v>0$, while the cost of the services is $c, c \geqslant 0$. The parameter $v$ is known to both parties, while initially only the agency is aware of $c$; thus, ex ante $P$ treats $c$ as a random variable with positive density $f(\cdot)$ on $R_{+}$. The players $P$ and $A$ interact to determine the agency's budget, $b_{A}$, in the following manner: $A$ makes a budget request $b \in R_{+}$, after which $P$ can either accept the request and set $b_{A}=b$, reject the request and thereby forgo the agency's services, or audit the agency at a cost of $k>0$. Following an audit, the true value of the agency's cost $c$ is revealed to $P$, so that $P$ will set the budget at $b_{A}=c$ and acquire the agency's services if $c \leqslant v$, and forgo the services if $c>v \cdot{ }^{3}$ Since the agency can make the budget request contingent on the true value of $c$, a budget strategy for $A$ is a function

$$
\boldsymbol{\beta}: \boldsymbol{R}_{+} \rightarrow \boldsymbol{R}_{+},
$$

where $\beta(c)$ is the budget requested by the agency if the true cost is $c$. After observing the agency's request, the politician makes the audit/accept/reject deci-

${ }^{3}$ In principle, $P$ could set any budget following an audit; however, in any sequential equilibrium $P$ 's response will be as specified. 
sion, where we allow $P$ to randomize in this decision. Thus, an audit strategy for $P$ is a function

$$
\alpha: \boldsymbol{R}_{+} \rightarrow[0,1]^{2},
$$

where $\alpha(b)=\left(\alpha_{1}(b), \alpha_{2}(b)\right)$, and $\alpha_{1}(b)$ is the probability that $P$ accepts a request of $b, \alpha_{2}(b)$ is the probability that $P$ audits, and $1-\alpha_{1}(b)-\alpha_{2}(b)$ is the probability that $P$ rejects.

We assume that both parties are risk-neutral, with $A$ interested in maximizing the expected budget surplus, and $P$ maximizing the value of the agency net of the budget as well as any audit costs. ${ }^{4}$ Thus, the expected utility for $A$ from requesting a budget of $b$, given true cost $c$ and auditing strategy $\alpha$ by $P$, is

$$
E U_{A}(b, c ; \alpha)=\alpha_{1}(b)(b-c) .
$$

Similarly, the expected utility for $P$ from accepting a budget request $b$ with probability $a_{1}$ and auditing with probability $a_{2}$, given posterior beliefs $\mu$ concerning the value of $c$, is

$$
E U_{P}(b, a ; \mu)=a_{1}(v-b)+a_{2}\left[v-c_{\mu}-k\right],
$$

where $c_{\mu}=\int c \mu(c \mid b) d c$.

We analyze this situation by examining a subset of the set of sequential equilibrium strategies for the players (Kreps and Wilson 1982). ${ }^{5}$ A sequential equilibrium consists of strategies $\beta^{*}, \alpha^{*}$, and beliefs $\mu^{*}$, such that (i) for all $c \in$ $R_{+} \beta^{*}(c)$ maximizes $E U_{A}\left(b, c, \alpha^{*}\right)$; (ii) for all $b \in R_{+}, \alpha^{*}(b)$ maximizes $E U_{P}(b$, $\left.a, \mu^{*}\right)$; and (iii) if $\beta^{*-1}(b) \neq \phi$, then $\mu^{*}(b)$ satisfies Bayes's rule according to the budget strategy $\beta^{*}$ and the prior $f(\cdot)$.

To solve for the equilibria, we identify a critical value of auditing costs. Let $k^{\prime}$ solve

$$
\int_{0}^{v} c f(c) d c / \int_{0}^{v} f(c) d c=v-k
$$

so that if $k=k^{\prime}, P$ is indifferent between accepting and auditing a budget of $v$ requested by all $c \in[0, v]$. The following two results characterize the player's equilibrium behavior for $k \geqslant k^{\prime}$ and for $k<k^{\prime}$, and are proven in Banks (1989). ${ }^{6}$

4As Banks (1989) notes, the equilibrium behavior of $P$ and $A$ is unchanged if $A$ were interested in maximizing the budget, rather than the budget surplus, subject to the constraint that the budget be at least as great as the cost of production. Further, Banks (1989) shows that assuming $P$ and $A$ are risk-averse, rather than risk-neutral, does not qualitatively effect the results either.

'Propositions 1 and 2 below characterize those sequential equilibria that are universally divine (Banks and Sobel 1987).

${ }^{6} \mathrm{Clearly}$, by the description of the agency's preferences, we can ignore the behavior of cost types $c>v$ in the determination of equilibrium strategies, since these types will never request a budget less than $v$ if such a request is accepted with positive probability. However, the presence of such types will be important for the comparative statics results to follow, since as the value of the agency, $v$, increases more cost types will subsequently be able to transact with $\boldsymbol{P}$ at a positive budget surplus. 
Proposition 1: If $k \geqslant k^{\prime}$, then the following constitute sequential equilibrium strategies:

$\beta^{*}(c)=v, \forall c \in[0, v]$

$\alpha_{1}(b)=1, \forall b \leqslant v$.

Thus, if the cost of auditing an agency is sufficiently high, the agency requests a budget equal to $v$, and the politician accepts it with probability one. In these cases, it is simply not worth the auditing costs for the politician to determine the agency's real costs and set its budget at this level.

To solve the case where $k<k^{\prime}$, we define $c^{\prime}$ as the cost that solves the following:

$$
G(\tilde{\mathbf{c}}, k, v) \equiv\left[\int_{\tilde{c}}^{v} c f(c) d c / \int_{\tilde{c}}^{v} f(c) d c\right]-v+k=0
$$

This says that if $A$ sets $\beta(c)=v$ if and only if $c \in\left[c^{\prime}, v\right]$, then $P$ will be indifferent between accepting and auditing upon observing a budget request of $b=v$.

Proposition 2: If $k<k^{\prime}$, then the following constitute sequential equilibrium strategies:

$$
\begin{aligned}
& \beta^{*}(c)= \begin{cases}c+k & \text { if } c \in\left[0, c^{\prime}\right) \\
v & \text { if } c \in\left[c^{\prime}, v\right],\end{cases} \\
& \alpha_{1}^{*}(b)= \begin{cases}1 & \text { if } b \leqslant k \\
\exp \{(k-b) / k\} & \text { if } b \in\left[k, c^{\prime}+k\right], \\
0 & \text { if } b \in\left(c^{\prime}+k, v\right) \\
\exp \left\{c^{\prime} / k\right\} k /\left(v-c^{\prime}\right) & \text { if } b=v\end{cases} \\
& \alpha_{2}^{*}(b)=1-\alpha_{1}^{*}(b) .
\end{aligned}
$$

Thus, if $c \leqslant c^{\prime}$ the agency sets its budget request equal to its true cost of production plus the costs of auditing, $b=c+k$. For $b \in\left[k, c^{\prime}+k\right]$, then, $P$ is able to invert $A$ 's budget strategy and hence is aware of the true cost when making the auditing decision. The requested budget is such that $P$ is indifferent between accepting and auditing, implying that adopting the equilibrium mixed strategy is optimal. Further, the auditing schedule is chosen to give the agency with cost $c$ $\leqslant c^{\prime}$ the incentive to reveal this information. In particular, higher budget requests are audited more often, thereby giving the agency the incentive to request $b=c$ $+k$ rather than some higher amount. Cost types $c \in\left(c^{\prime}, v\right]$ pool at the request $b$ $=v$, implying that $P$ is able to make only a limited inference concerning the value of $c$. The politician audits the request $b=v$ more often than any other (equilibrium) request, again providing the incentive for the agency to adopt the budget strategy, $\beta^{*}$. This is illustrated in Figure 1.

The above propositions describe the equilibrium behavior of the politician and the agency as a function of the auditing cost $k$, value of the agency $v$, the 
Figure 1. Equilibrium Budget Strategy $\left(k<k^{\prime}\right)$

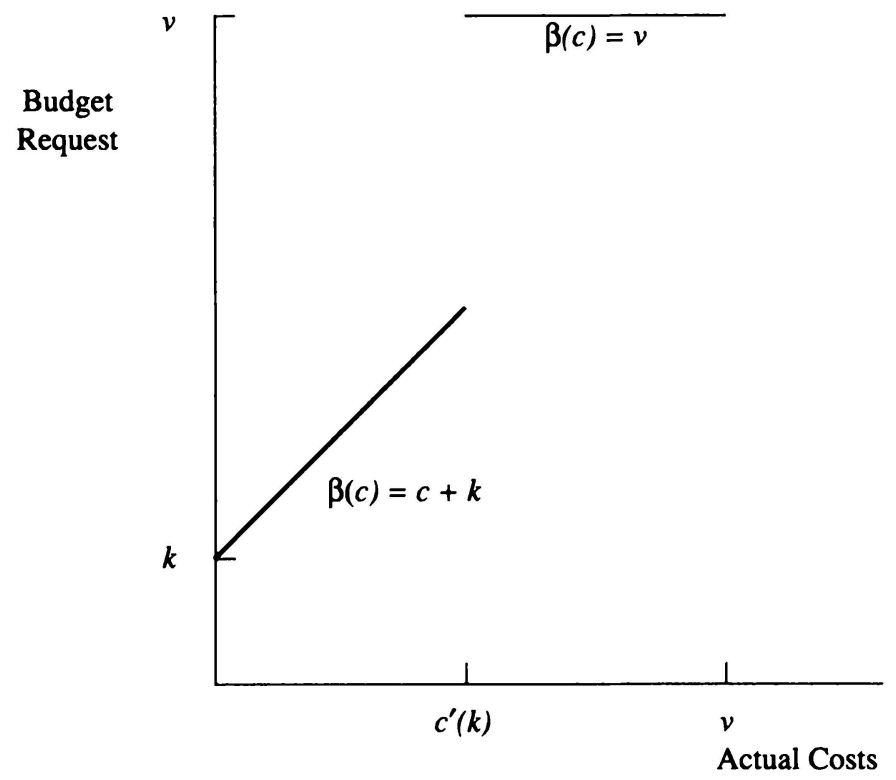

prior probability $f(\cdot)$, and true agency cost $c$. If $k<k^{\prime}$, the ability of the agency to extract large budgets through its control of the budgetary agenda is mitigated by the possibility that the politician will incur a cost and subsequently eliminate any informational asymmetry, and hence any budget surplus. If on the other hand $k \geqslant k^{\prime}$, then such a possibility will not occur in equilibrium, thus allowing the agency to "monopoly price" its services to the politician.

\section{Agency Selection}

The model and the subsequent equilibrium behavior derived in the previous section form the basis for the politicians' selection of an "optimal" agency, since now we can describe the politician's preferences over the set of potential agencies. From an ex ante perspective, we can view an agency as being characterized by an auditing cost $k$, an agency value $v$, and a prior probability distribution $f(\cdot)$. In what follows, we focus attention on $k$ and $v$, since (as we shall argue) these variables are directly related to the role of interest groups.

From Propositions 1 and 2 above we see that if the pair $(k, v)$ is such that $k$ $\geqslant k^{\prime}$, then the politician receives a zero net return from the agency, while if $(k$, $v$ ) is such that $k<k^{\prime}$, then the politician receives a positive net return from the agency, since for low agency costs the budget will be equal to either $c$ (if audited) or some value between $c$ and $v$ (if accepted). Further, the magnitude of this return will be a function of both the auditing cost $k$ and the value of the agency $v$. Let 
$U(k, v)$ denote the ex ante expected utility of $P$ generated by the equilibrium behavior described in the above propositions. Then,

$$
U(k, v)= \begin{cases}\int_{0}^{c^{\prime}}(v-c-k) f(c) d c & \text { if } k<k^{\prime} \\ 0 & \text { if } k \geqslant k^{\prime}\end{cases}
$$

where $c^{\prime}$ is a function of both $k$ and $v$, and $k^{\prime}$ is a function of $v$. Given that the politician will be selecting an agency to maximize $U(k, v)$, we can safely ignore those agencies where $k \geqslant k^{\prime}$, since as long as one agency exists such that $k<k^{\prime}$ the politician would never choose an agency where $k \geqslant k^{\prime}$.

To derive the politician's preferences over potential agencies we first examine the effect of changes in the underlying parameters $(k, v)$ on the ex ante expected utility generated by the agency, $U(k, v)$. This yields the following result.

Proposition 3: If $k<k^{\prime}$, then $\partial U / \partial k<0$.

Proof: Differentiating $U(k, v)$ with respect to $k$, we get (by Liebnitz's rule)

$$
\frac{\partial U}{\partial k}=\frac{\partial c^{\prime}}{\partial k}\left(v-c^{\prime}-k\right) f\left(c^{\prime}\right)-\int_{0}^{c^{\prime}} f(c) d c .
$$

Implicit differentiation then gives us that

$$
\frac{\partial c^{\prime}}{\partial k}=-\frac{\partial G / \partial k}{\partial G / \partial c^{\prime}} .
$$

Since $\partial G / \partial k=1$ and

$$
\frac{\partial G}{\partial c^{\prime}}=\int_{c^{\prime}}^{v}\left(c-c^{\prime}\right) f(c) d c /\left[\int_{c^{\prime}}^{v} f(c) d c\right]^{2}>0,
$$

we have that $\partial U / \partial k<0$. QED

Proposition 3 shows that, for a fixed value of an agency, the politician prefers those agencies with lower auditing cost. The argument behind this result is straightforward given the equilibrium behavior described in Proposition 2: as $k$ increases more cost types are able to extract the maximum budget (i.e., they pool at $b=v$ ), thus depriving $P$ of any positive net return. In addition, any budgets requested by cost types $c<c^{\prime}$ are larger, again shrinking $P$ 's return from the transaction. Hence, holding fixed the value of the agency, the politician prefers agencies with a lower auditing cost, since such agencies can extract only a negligible portion of the surplus, leaving the lion's share to the politician. This is illustrated in Figure 2 for $\hat{k}<k<k^{\prime}$.

With regard to the value of the agency to the politician, $v$, we have that

$$
\frac{\partial U}{\partial v}=\frac{\partial c^{\prime}}{\partial v}\left(v-c^{\prime}-k\right) f\left(c^{\prime}\right)+\int_{0}^{c^{\prime}} f(c) d c
$$


Figure 2. Comparative Statics

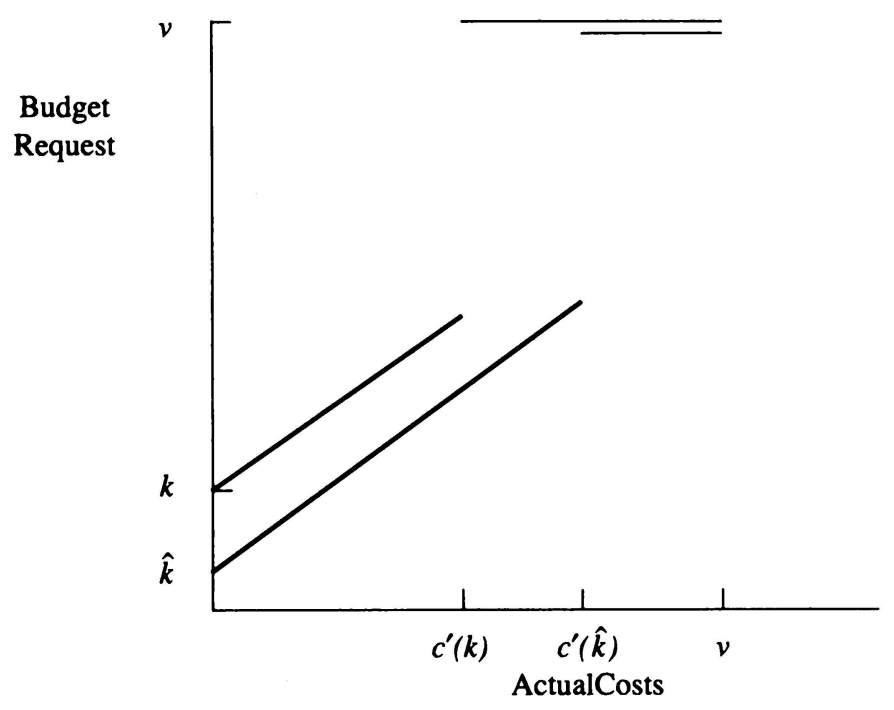

In this case however the sign of $\partial c^{\prime} / \partial v$ will depend on the prior $f(\cdot)$; in particular, $\partial c^{\prime} / \partial v \geqslant 0$ if and only if

$$
\left[\int_{c^{\prime}}^{v} f(c) d c\right]^{2} \geqslant f(v) \int_{c^{\prime}}^{v}(v-c) f(c) d c .
$$

Thus, if equation (8) holds then $\partial U / \partial v>0$. On the other hand, if $\partial c^{\prime} / \partial v<0$, the sign of $\partial U / \partial v$ will in general depend on the following trade-off: as $v$ increases, fewer types separate; but for those that do, the return to $P$ is larger. Thus, if $f\left(c^{\prime}\right)$ is relatively large, then $P$ may not prefer a marginal increase in $v$, since this would imply an unacceptably large fraction of cost types switching to the pooled budget request of $b=v$. Still, we can sign $\partial U / \partial v$ for a range of parameters depending on the prior $f(\cdot)$, since for any $f(\cdot)$ there exists a value of the auditing cost $k^{f}$ such that if $k \leqslant k^{f}$ then $\partial U / \partial v>0$. To see this, note that if $k=0$ then $c^{\prime}$ $=v$, so that by equation (7) $\partial U / \partial v>0$. Since $c^{\prime}$ is continuous in $k$, for $k$ small the result follows, where clearly the definition of "small" depends on the prior $f(\cdot)$.

The preceding analysis describes the preferences of our representative politician over a set of potential agencies, where an agency is parameterized by the pair $(k, v)$. Given such a set, then, we can characterize the politician's optimal choice of agency. Let $\Omega \subseteq R_{+}^{2}$ denote the set of feasible agencies, and let $\left(k^{*}\right.$, $\left.v^{*}\right)$ denote the optimal choice of agency in $\Omega$; that is, if the politician were al- 
lowed to select but a single agency to form, his or her choice would be the agency characterized by the parameters $\left(k^{*}, v^{*}\right)$. From the comparative statics results above, we know $\left(k^{*}, v^{*}\right)$ is such that there does not exist $(k, v) \in \Omega$ where $k<$ $k^{*}$ and $v=v^{*}$. Thus, the optimal agency will be such that no other agency exists that generates the same value while possessing a lower cost of auditing. Further, if equation (8) holds or if $k^{*} \leqslant k^{f}$, then there will exist no $(k, v)$ such that $k=k^{*}$ and $v>v^{*}$; no other agency exists that possesses the same auditing cost while generating a higher value.

One of the interesting implications of the optimal choice of agency by the politician concerns the ex ante probability that an audit occurs, where we denote this by $\pi(k, v)$. For $k<k^{\prime}$ this is (from Proposition 2)

$$
\begin{aligned}
\pi(k, v)= & \int_{0}^{c^{\prime}}(1-\exp \{-c / k\}) f(c) d c \\
& +\left[1-\exp \left\{-c^{\prime} / k\right\} k /\left(v-c^{\prime}\right)\right] \int_{c^{\prime}}^{v} f(c) d c .
\end{aligned}
$$

Holding $c^{\prime}$ fixed, we see that both of these terms are decreasing in $k$, so that for cost types $c \neq c^{\prime}$ as $k$ increases the probability of an audit decreases. However, since $\partial c^{\prime} / \partial k<0$, some cost types are switching from separating at $b=c+k$ to pooling at $b=v$, where the latter is audited more often. Hence, the sign of $\partial \pi /$ $\partial k$ will in general depend on the prior; a similar conclusion holds for $\partial \pi / \partial v$. Consider the following restriction on the prior $f(\cdot)$ :

$$
\int_{c^{\prime}}^{v} f(c) d c \geqslant f\left(c^{\prime}\right)\left(v-c^{\prime}\right)
$$

a condition that is satisfied if, for example, $f\left(c^{\prime}\right)$ is not too large or $f(\cdot)$ is nondecreasing on $\left(v-c^{\prime}, v\right)$. Banks (1989) shows that if equation (10) is satisfied then $\partial \pi / \partial k<0$. In addition, if equation (8) holds as well, then $\partial \pi / \partial \nu>0$. Now recall that the politician's preferences over the set of feasible agencies, $\Omega$, imply minimizing with respect to $k$ and (for low $k$ ) maximizing with respect to $v$. Therefore, by the comparative statics results above, both of these directions lead to an increase in the ex ante probability of an audit occurring. Hence, an implication of the politicians' optimal selection of an agency is to guarantee a relatively high amount of agency auditing.

\section{Interest Groups and Regulatory Agency Performance}

Thus far, we have left the variables $k$ and $v$ abstract without much discussion of their empirical referents. One way to think of these variables is as being derived from a set of more fundamental variables and decisions related to agencies and interest groups. For the variable $v$, this concept is not novel; $v$ is a function of both the benefits the agency generates for the relevant interest group constitu- 
ency as well as the ability of this group to translate those benefits into the electoral rewards the politician covets. Our view is that the auditing cost $k$ is similarly a function both of the technological considerations or gross costs of monitoring the agency as well as the ability of the relevant interest group to monitor the choices and performance of the agency and convey politically relevant information to politicians. Such a concept parallels the notion of "fire alarms" in McCubbins and Schwartz (1984) and the related notion of a "constituency trigger" in Weingast (1984). According to this view, politicians cannot hope to monitor hundreds of agencies by themselves and, instead, rely on their constituents to do so. When something goes wrong, constituents pull a "fire alarm" that brings politicians to their aid. This in turn provides the incentives for agencies to satisfy the relevant constituencies, for those agencies that do not risk the wrath of political intervention. Thus, politicians act through the threat of the "big club behind the door" that is triggered by their constituents (Weingast and Moran 1983). As this literature points out, the club need not be used frequently to be effective.

Hence, the ability to assure the benefits of regulation are realized by constituents, and the ability to subsidize auditing costs given a level of gross costs, can be seen as a function of the organization of the relevant interest groups. Thus, we can describe the politician-relevant variables $k$ and $v$ as $v=v(b, x)$, and $k=k(t$, $x$ ), where the vector $b$ summarizes the benefits to the constituency an agency generates, $t$ represents the difficulty of monitoring the agency, and $x$ measures the degree of cohesion in the interest groups. ${ }^{7}$ Therefore, the general characterization of an agency is by the vector $(b, t, x)$. By design the effect of these variables on the politician-relevant variables $k$ and $v$ is as follows:

1. $\partial v / \partial b>0$, and $\partial k / \partial t>0$, so that given a level of organization, the electoral rewards to a politician increase in benefits and the auditing cost increases in difficulty;

2. $\partial v / \partial x>0$, so that given a level of benefits the electoral rewards increase in interest group organization;

3. $\partial k / \partial x<0$, so that given a degree of auditing difficulty the politician's auditing cost decreases in interest group organization.

As we have pointed out, most scholars who link interests groups and regulation have focused on $v$, the value of the decision to the politicians generated, in our model, via the electoral rewards provided by the interest group. Our model yields the comparative statics result for some values of the parameters, namely, $\partial U / \partial v>0$; that is, the larger the electoral rewards, the more attractive is the agency to the politicians, a result that parallels that found in Stigler (1971) and

'More realistically, $x$ might represent a vector of parameters that characterize an interest group and its environment by politically relevant components. It should be obvious how to generalize the discussion that follows in a natural way. 
Peltzman (1976). In addition, the above discussion generates a further conclusion: ceteris paribus (i.e., fixed $k$ and $b$ ), the more organized an interest group is the more likely it is to receive beneficial regulation.

Absent from most discussions, however, is a second critical variable, namely, the auditing cost faced by the politician. Given that the variable $k$ is a function of the interest groups' degree of organization, the "ceteris paribus" assumption above concerning $k$ is untenable, since in essence this assumes that the variable $t$ changes to offset the change in $x$. However, as noted above, $\partial k / \partial x<0$, so that since $\partial U / \partial k<0$, the effect of an increase in organization through the auditing cost is beneficial to the politician as well. Thus, the model highlights the twin (and complementary) effects of an organized interest group: ceteris paribus (i.e., fixed $b$ and $t$ ), organized groups are better able to translate the benefits generated by the agency into electoral rewards for the politician; further, because they can more effectively monitor the agency's performance, they allow a larger proportion of those rewards to accrue to the politician.

Another implication of disentangling the politician-relevant variables $(k, v)$ into their more primitive elements $(b, t, x)$ is to explain the existence of certain agencies that might otherwise not be justified. Consider for example the Consumer Products Safety Commission, an agency that attempts to service a large set of "consumers," but whose associated interest group (the aforementioned consumerists) is relatively diffuse. Traditional analysis seems to predict that such an agency could not be sustained, given the inability of the interest group to generate electoral rewards for the relevant politicians. However, the current model posits the existence of a second source of an interest group's influence with respect to a politician, namely, through the interest group's ability to monitor the agency's performance. If the technology inherent in monitoring an agency, captured by the variable $t$, is such that a diffuse interest group (or, possibly, an organized subset of the group) can still generate a sufficiently low auditing cost for the politician, then such an agency is more likely to be sustained. Hence, a relatively disorganized interest group (e.g., the public at large) will receive the benefits of regulation (e.g., the CPSC) when its ability effectively to monitor the agency offsets its inability to translate those benefits into electoral rewards.

Alternatively, the model also suggests that an agency generating high levels of benefits and a well-organized interest group to translate such benefits into electoral rewards are not sufficient to guarantee the maintenance of such an agency. If technological considerations are such that regardless of the degree of cohesion in the group the politician's auditing cost $k$ remains high, then such an agency will not persist, since most of the electoral rewards will go to the agency itself, in the form of an inflated budget, rather than the constituents and the politician. 


\section{Conclusion}

To understand the performance of regulatory agencies, we must begin with the politicians who create them. It is unlikely that politicians would again and again create bureaus that are able to extract the entire value of their services. Perhaps the creation of some agencies of this sort can be explained for symbolic reasons - their value is solely in their creation so that ex post problems might not matter. However, it is unlikely that the large bureaucracies of most Western governments can be explained in this manner.

If information asymmetries are potentially advantageous to agencies, then politicians either will look for ways to mitigate this problem or will not create the agencies in the first place. The key to understanding our model is that not all potential agencies have the same possibilities for exploiting their position. This suggests that those agencies that have a significant potential to extract rents from politicians will simply not be created. The agencies that are created, therefore, by and large will provide significant benefits to politicians (and their constituents) with only limited amounts captured for themselves. Put simply, this argument implies that there exists a strong selection effect at work in the process of agency creation: while bureaucratic discretion is a big problem for some potential agencies, politicians are far less likely to create such agencies.

The model analyzed in this paper builds on several traditions in the literature on regulation: that of asymmetric information potentially exploitable by agencies; that of focusing on politicians who seek ways to mitigate agency exploitation; and that of focusing on the service of regulatory agencies to interest groups. What this paper provides is a unified approach to the study of these traditions. With regard to the service of interest groups, our model suggests that politicians find organized interest groups attractive for two reasons, not one: (1) because they provide electoral rewards and (2) because they monitor and help police agencies. Thus, even if there exists a diffuse constituency that provided the same electoral reward to politicians as an organized one, politicians would favor the latter because it provides the means for policing the delivery of benefits.

Two implications follow from this. First, even if a diffuse group could provide sufficient electoral rewards for politicians to consider creating an agency, politicians may not do so because, ex post, they could not prevent the agency from exploiting its information position vis-à-vis the unorganized constituency. If politicians cannot prevent the agency from extracting all the rents of its services, politicians will not create them.

The second implication that follows from our approach concerns inefficiency. The standard source of efficiency loss in interest group models hinges on differential electoral rewards: because certain industries can organize support of cartelizing regulation in ways that their consumers cannot effectively oppose, 
interest groups can lead to efficiency losses (cf. Stigler 1971; Peltzman 1976). Our model has little new to say about this source of inefficiency and, instead, identifies a second source. Namely, the main source of inefficiency in our model is not due to service to interest groups but rather from those agencies that are systematically not created because, ex post, there is no way to police them adequately.

Our approach has implications for fire alarm type oversight as well. The last result of section 2 showed that as $k$ falls, the probability of auditing increases. At the same time, as $k$ falls, the amount of a deviation between true costs, $c$, and the budget requested, $\beta(c)$, falls on average. In comparison with an agency associated with a high cost of auditing, an agency with a low cost of auditing will exhibit more frequent audits and, hence, adjustments in budgets, but with the expected adjustment being smaller. This implies frequent communication between politicians and their constituents, resulting in frequent budget adjustments. However, this does not necessarily mean more "oversight" in the sense of an explicit investigation by politicians into the nature of agency decisions. The main point of the above analysis is that "auditing" may take place through investigation by a constituency who then communicates the results to politicians rather than through a formal investigation by politicians.

Another aspect of the politician-agency-interest group relationship is that even though it is politicians, not agencies, that choose which constituencies to benefit, we should observe little direct interaction between politicians and agencies when the system works well. Policing agencies requires participation by both politicians and constituents, and it is typically the latter that interact with the agency on a regular basis.

Finally, our view provides a new interpretation of the hypothesis prominent among political scientists and historians that we have labeled "cartel by design." According to this theory, agencies serve interest groups from inception, and doubtless there are many instances of this. According to our model, however, not all agencies that serve regulated interests do so by design. This view holds that the Interstate Commerce Commission (ICC) only came to serve the regulated interests long after its inception. The ICC was instead originally designed to serve farmers and shippers. The latter, because they were diffuse groups, did not provide the constant monitoring and electoral rewards necessary to maintain the flow of agency benefits. As their political relevance declined (falling $v$ and rising $k$ ) while that of the railroads did not, the latter came to dominate regulatory proceedings and hence "capture" the ICC. ${ }^{8}$ In this way our interpretation poten-

'For a review of the literature on the ICC as well as a synthetic treatment that provides a new view, see Gilligan, Marshall, and Weingast (1989). This paper also argues that the two views noted in the current text are not inconsistent, but instead provide partial explanations that need to be combined in the appropriate manner. 
tially allows the use of comparative statics from the model to study changes in agency behavior over time.

Manuscript received 18 May 1989

Final manuscript submitted 8 August 1991

\section{REFERENCES}

Banks, Jeffrey. 1989. “Agency Budgets, Cost Information, and Auditing." American Journal of Political Science 33:670-99.

Banks, Jeffrey, and Joel Sobel. 1987. "Equilibrium Selection in Signaling Games." Econometrica 55:647-61.

Becker, Gary. 1983. "A Theory of Competition among Pressure Groups for Political Influence." Quarterly Journal of Economics 98:371-400.

Bendor, Jon, Serge Taylor, and Roland Van Gaalen. 1985. "Bureaucratic Expertise vs. Legislative Authority: A Model of Deception and Monitoring in Budgeting." American Political Science Review 79:1041-60.

-1987. "Politicians, Bureaucrats, and Asymmetric Information." American Journal of Political Science 31:796-828.

Bernstein, Marver. 1955. Regulating Business by Independent Commission. Princeton: Princeton University Press.

Calvert, Randy, Mathew McCubbins, and Barry Weingast. 1989. "A Theory of Political Control of Agency Discretion." American Journal of Political Science 33:588-610.

Fiorina, Morris P. 1981. "Congressional Control of the Bureaucracy: A Mismatch of Incentives and Capabilities." In Congress Reconsidered, ed. Lawrence Dodd and Bruce Oppenheimer. Washington, DC: Congressional Quarterly Press.

- 1985. "Group Concentration and the Delegation of Legislative Authority." In Regulatory Policy and the Social Sciences, ed. Roger G. Noll. Berkeley: University of California Press.

Gilligan, Thomas, William Marshall, and Barry R. Weingast. 1989. "Regulation and the Theory of Legislative Choice: The Interstate Commerce Act of 1887." Journal of Law and Economics 32:35-61.

Huntington, Sam. 1952. "The Marasmus of the ICC." Yale Law Journal 61:467-509.

Kolko, Gabriel. 1965. Railroads and Regulation, 1877-1918. New York: Norton.

Kreps, David, and Robert Wilson. 1982. "Sequential Equilibria." Econometrica 50:863-94.

McCubbins, Mathew. 1985. "Legislative Design of Regulatory Structure." American Journal of Political Science 29:721-48.

McCubbins, Mathew, Roger G. Noll, and Barry R.Weingast. 1989. "Structure and Process as Solutions to the Politician's Principal-Agency Problem." Virginia Law Review 74:431-82.

McCubbins, Mathew, and Thomas Schwartz. 1984. "Congressional Oversight Overlooked: Police Patrols vs. Fire Alarms." American Journal of Political Science 28:165-79.

Miller, Gary, and Terry Moe. 1983. "Bureaucrats, Legislators, and the Size of Government." American Political Science Review 77:297-322.

Mitnick, Barry. 1980. Political Economy of Regulation. New York: Columbia University Press.

Moe, Terry. 1984. "The New Economics of Organization." American Journal of Political Science 28:739-77.

1989. "The Politics of Bureaucratic Structure." In Can the Government Govern? ed. John Chubb and Paul Peterson. Washington, DC: Brookings Institution.

Noll, Roger G. 1989. "Economic Perspectives on the Politics of Regulation." In Handbook of Industrial Organization, ed. Richard Schmalensee and Robert Willig. Amsterdam: North-Holland. 
Noll, Roger G., and Bruce Owen. 1983. The Political Economy of Regulation. Washington, DC: American Enterprise Institute.

Niskanen, William. 1971. Bureaucracy and Representative Government. Chicago: Aldine Press.

Peltzman, Sam. 1976. "Towards a More General Theory of Regulation." Journal of Law and Economics 19:211-40.

Spitzer, Matthew. 1985. "Rational Choice Political Economy and Administrative Law: One View of the Synagogue." Manuscript, University of Southern California Law Center.

Stigler, George. 1971. "The Economic Theory of Regulation." Bell Journal of Economics 2:3-21.

Weingast, Barry R. 1984. "The Congressional Bureaucratic System: A Principal-Agent Perspective (with Applications to the SEC)." Public Choice 44:147-91.

Weingast, Barry R., and Mark J. Moran. 1983. "Bureaucratic Discretion or Congressional Control: Regulatory Agency Policy Making at the FTC." Journal of Political Economy 91:765-800.

Wilson, James Q. 1974. "The Politics of Regulation." In Social Responsibility and the Business Predicament, ed. James McKee. Washington, DC: Brookings Institution.

1980. The Politics of Regulation. New York: Basic Books. 